\title{
Effects of knowing the task duration on players' pacing patterns during soccer small-sided games
}

\section{Ricardo Ferraz, Bruno Gonçalves, Roland Van Den Tillaar, Sergio Jiménez Sáiz, Jaime Sampaio \& Mário Cardoso Marques}

To cite this article: Ricardo Ferraz, Bruno Gonçalves, Roland Van Den Tillaar, Sergio Jiménez Sáiz, Jaime Sampaio \& Mário Cardoso Marques (2017): Effects of knowing the task duration on players' pacing patterns during soccer small-sided games, Journal of Sports Sciences, DOI: 10.1080/24733938.2017.1283433

To link to this article: http://dx.doi.org/10.1080/24733938.2017.1283433

Submit your article to this journal $\asymp$

View related articles \ulcorner

View Crossmark data $₫$ 


\title{
Effects of knowing the task duration on players' pacing patterns during soccer small-sided games
}

\author{
Ricardo Ferraz $\mathbb{1}^{\mathrm{a}, \mathrm{b}}$, Bruno Gonçalves $\mathbb{1}^{\mathrm{b}}$, Roland Van Den Tillaarc, Sergio Jiménez Sáiz ${ }^{\mathrm{d}}$, Jaime Sampaio $\mathbb{1}^{\mathrm{b}}$ \\ and Mário Cardoso Marques (1)
}

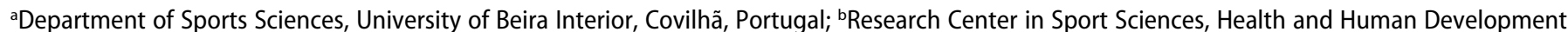
(CIDESD), Vila Real, Portugal; ' Department of Teacher Education, Nord Trøndelag University College, Levanger, Norway; ${ }^{\mathrm{d} F a c u l t a d}$ de Ciencias de la Actividad Física y el Deporte, Universidad Europea de Madrid, Madrid, Spain

\begin{abstract}
The aim of this study was to identify the influence of prior knowledge of exercise duration on players' pacing patterns during soccer small-sided games. Twenty semi-professional male soccer players participated in this study. In the first game scenario, players were not informed how long they would be required to play the small-sided game and the activity was terminated after 20 min (Unknown Condition). In the second game scenario, players were told that they would play the small-sided game for $10 \mathrm{~min}$, but immediately after completing the 10-min game, they were asked to complete another $10 \mathrm{~min}$ (Partially Condition). In the third game scenario, players were instructed that they would play the small-sided game for 20 min and then they completed the 20-min game (Known Condition). The results presented a tendency of higher values in all performance variables in the $\left[0^{\prime}-10^{\prime}\right]$ min compared with the $\left[10^{\prime}-20^{\prime}\right] \mathrm{min}$. As the players' previous knowledge about the tasks duration increased, the performance between two moments tended to be similar. Considering the entire 20-min game duration, the Partially Condition of the exercise was the most demanding condition. In conclusion, the knowledge of shorter durations of the exercise seems to lead to an increase of exercise duration demand, and longer exercise durations possibly tend to decrease differences between full knowledge and not knowing the exercise duration.
\end{abstract}

ARTICLE HISTORY Accepted 28 November 2016

\section{KEYWORDS}

Fatigue; anticipation; psychophysiology; intermittent exercise; perception of effort; regulation of effort

\section{Introduction}

Fatigue effects in high intensity, intermittent team sports and particularly in soccer is of substantial interest and discussion (Waldron \& Highton, 2014). Mohr, Krustrup and Bangsbo (2005) have previously reviewed the topic of fatigue with reference to soccer performance, describing the temporal running patterns of players during matches and proposing a variety of responsible physiological mechanisms. Until recently, fatigue in matches was attributed to several individual physiological and psychological factors such as blood lactate and $\mathrm{H}+$ accumulation, glycogen depletion, $\mathrm{PCr}$ depletion, dehydration, failure of neural transmission, motivational and mental mechanisms, or contextual and tactical factors (Edwards \& Polman, 2014; Mohr et al., 2005; Waldron \& Highton, 2014). The theory of terminal fatigue (i.e., depletion system capacity) has been proposed within various individual physiological systems (Mohr et al., 2005; Mohr, Krustrup, \& Bangsbo, 2003; Reilly, Drust, \& Clarke, 2008); however, the topic of fatigue in team sports seems to have been updated recently, due to the possible effects of pacing, already demonstrated in continuous sports (Ferraz, Van Den Tillaar, \& Marques, 2012; Millet, 2011; Waldron \& Highton, 2014).

Although the topic is still understudied, recent studies have confirmed the possibility that other mechanisms aside from physiological ones may contribute to the understanding of the fatigue effects, giving importance to pacing and psychophysiological theoretical approaches (Billaut, Bishop, Schaerz, \& Noakes, 2011; Edwards \& Polman, 2014; Ferraz et al., 2012; Ferraz, Van Den Tillaar, \& Marques, 2015; Ferraz, Van Den Tillaar, Pereira, \& Marques, 2016; Gabbett, Walker, \& Walker, 2015; Marcora, 2008, 2009; Millet, 2011; Waldron \& Highton, 2014). Generally, the concept of pacing is defined by Gabbett et al. (2015) as the management and strain distribution during an exercise in which the player, consciously and unconsciously, tries to complete the activity in a reasonable physiological state, controlling the onset of fatigue. Afferent sensations are sent from the musculoskeletal and cardiovascular systems to the central nervous system, where the pacing pattern is altered based on the brain's interpretation of the perceived exertion (Edwards \& Noakes, 2009; Gabbett et al., 2015). This concept of pacing also applies to soccer, according previous topics of temporary fatigue during team sports matches, but suggests and adds alternative mechanisms for the observed fluctuations in match-running performance based on the psychophysiological system (Edwards \& Polman, 2014; Waldron \& Highton, 2014). The concept of pacing is also connected with the decision-making theory application based on rational decision-making model by Simon (1955) as suggested by Renfree, Martin, Micklewright and Gibson (2014). These authors proposed that the decision to reduce, increase or maintain efferent neural drive depends on the 
perceived benefits to be obtained from each alternative, which is based on the when perceived "payoff" is potentially large (e.g., victory, achieving a personal best, enjoyment of the experience, knowledge about exercise duration) an athlete would be more likely to incur a greater degree of homeostasis disruption. This view does not diminish the importance of physiological behaviour, but it specifies and enhances the crucial role of the brain in the regulation of physical effort. The knowledge of the activity in addition to various forms of feedback sensations determines the psychophysiological and decision-making processes controlled by the brain (Edwards \& Polman, 2014).

For example, various pacing profiles seem to ]acterise match running performance among soccer players (Waldron \& Highton, 2014). Whole-match players supposedly adopt a "slow positive" pacing profile, characterised by a gradual decline in total and high-intensity running. In contrast, partmatch players are thought to select either "all-out" or "reserve" strategies, depending on their role in the match, although this all-out end spurt may not be a common event. Additionally, it seems that the brain initiates a strategy at the start of a match, based on both the knowledge of the duration of the game and prior experience. Recently, Waldron and Highton (2014) demonstrated that team-sport athletes that are required to compete for relatively short periods (e.g., substitutes) set a higher initial pacing pattern and exhibited a significantly greater end spurt than athletes required to play the entire match. This suggests that shorter anticipated exercise periods are associated with greater playing intensities. In a more closed approach, Billaut et al. (2011) examined the influence of prior knowledge of sprint number on repeated-sprint exercise performance. The authors concluded that pacing occurs during repeated-sprint exercises in anticipation of the number of efforts that are expected to be included in the bout.

In fact, the knowledge of the duration initially employed in continuous sports is known as a significant factor in the pacing pattern and it has been not only demonstrated to be a major factor in the allocation of physiological and psychological resources during continuous exercise, but also recently applicable and investigated in intermittent exercise (Billaut et al., 2011).

Despite advances on this topic, few studies examined the influence of pacing as an explanation of the reduced work outputs in team sports. This is probably because of the difficulties in identifying an appropriate model that represents the complexity of the energetic demands and movement (Edwards \& Polman, 2014). Additionally, in team sports, it is difficult to isolate effects from the factors associated with the pacing concept.

Due to the general lack of experimental research at this purpose, more studies are needed. Objectively and about prior knowledge of exercise duration, only one study in rugby attempted to investigate its influence on the pacing patterns employed during game-based activities and the authors conclude that rugby players alter their pacing patterns based on the anticipated end point of the exercise bout (Gabbett et al., 2015). Nevertheless, it is difficult to generalise the conclusion of this study (Gabbett et al., 2015) to all team sports, because each one has its specificity and consequently is desirable to perform an analysis of the influence of duration knowledge of game exercise in soccer. Moreover, to understand the effect of knowledge, it is also important to control other possible variables directly or indirectly involved. In this study (Gabbett et al., 2015), verbal encouragement was used, which may have influenced some results. Furthermore, the time duration of exercise is a crucial point of analysis and it seems to be relevant to understand and compare what happens not only in shorter durations of exercise such as was considered but also in a perspective of longer durations.

Therefore, the purpose of this study was to investigate the influence of prior knowledge of exercise duration on the pacing pattern employed during game-based activities in soccer. The small-sided games were the method selected, due to their characteristics and their application in soccer training. Moreover, we tried to understand what happens in a longer time of exercise duration. We hypothesised that players alter their pacing pattern based on the knowledge of the exercise duration. Moreover, and based on findings of the other studies, we also hypothesised that players perform at higher intensities during an exercise of an anticipated shorter duration, and when the exercise is longer, the pacing pattern is to lower exercise intensity. However, it is also possible that at the end of the longer and known exercise, there will be an increase of intensity (Millet, 2011).

\section{Methods}

\section{Participants}

Twenty semi-professional male soccer players (age 21.9 years \pm 2.1 ; body height $1.80 \mathrm{~m} \pm 0.06$; body mass $75.7 \mathrm{~kg} \pm 5.8$ ) with 9.1 years \pm 3.8 of experience, playing in the second division of the Portuguese National Competition, participated in this study. All players performed five training sessions ( $90 \mathrm{~min}$ ) per week and played an official game during the weekend. All of them were fully informed about the protocol before participating in this study. Informed consent was obtained prior to all testing from all participants, in accordance with the approval of the regional ethical committee and with the principles of the Declaration of Helsinki.

\section{Design}

A cross-sectional field study and an adaptation of the Gabbett et al. (2015) protocol were used. Testing was conducted over four training sessions. The first session involved familiarisation of players with the game-based activity, equipment and procedures. Within 1 week of the familiarisation session, the players performed three randomised small-sided games separated by 7 days. In first game scenario, players were not told how long they would be required to play the small-sided game, but the activity was terminated after 20 min (Unknown Condition). In the second game scenario, players were told that they would play the small-sided game for 10 min, but immediately after completing the 10-min game, they were asked to complete another $10 \mathrm{~min}$ so that the total exercise duration was 20 min (Partially Condition). In the third game scenario, players were informed that they would play 
the small-sided game for $20 \mathrm{~min}$ and then completed the 20min game (Known Condition). In all four training sessions, the weather was sunny nearly with $18^{\circ} \mathrm{C}$ of temperature.

\section{Methodology}

A small-sided game was played in each session. Players were separated into four balanced teams of five players taking into account playing positions, tactical/technical levels and physical capacities. Teams' constitutions and respective opponents were maintained for each played condition. The small-sided game was played in a standardised ( $20 \mathrm{~m}$ wide $\times 40 \mathrm{~m}$ long) playing pitch without goalkeepers and any verbal encouragement. The objective was scoring goal. Multiple balls were positioned around the field so that in the case of a ball leaving the field, another was quickly introduced to ensure the game continued.

At the completion of each condition, players provided an overall rating of perceived exertion (RPE) using the Borg 6-20 scale (Borg, 1973). All players were familiar with the RPE scale and had previous experience rating the perceived exertion of training drills and small-sided games.

Players' tracking displacements were recorded by 20 GPS units working at a sampling frequency of $5 \mathrm{~Hz}$ (SPIPro X II, GPSports, Canberra, ACT, Australia) (Johnston et al., 2012). The processed variables were the total distance covered $(\mathrm{m})$, game pace (obtained by the players' average speed displacements) and total body impacts (McLellan, Lovell, \& Gass, 2011). In addition, three ratios were calculated to relate and compare the distance covered at high to very high (above $16 \mathrm{~km} \cdot \mathrm{h}^{-1}$ ), moderate $\left(10.0-15.9 \mathrm{~km} \cdot \mathrm{h}^{-1}\right)$ and low intensity $\left(7.0-9.9 \mathrm{~km} \cdot \mathrm{h}^{-1}\right)$ with distance covered at very low intensities $(0-6.9 \mathrm{~km}$. $\mathrm{h}^{-1}$ ), normalised for each $100 \mathrm{~m}$ for comparison purposes. These work-rest ratios are frequently used in the literature to describe activity profiles (Abade et al., 2014).

\section{Statistical analysis}

A descriptive analysis was performed using mean and standard deviations. The comparison among game conditions was assessed via standardised mean differences, computed with pooled variance and respective 90\% confidence intervals (Cumming, 2012; Hopkins, Marshall, Batterham, \& Hanin, 2009). Thresholds for ES statistics were 0.2, trivial; 0.6, small; 1.2, moderate; 2.0, large; and >2.0, very large (Hopkins et al., 2009). Differences in means, i.e., $\left[0^{\prime}-10^{\prime}\right]$ versus $\left[10^{\prime}-20^{\prime}\right]$ bouts for each condition, and comparison among the entire 20' condition, were expressed in percept units with $90 \%$ confidence limits $(C L)$. Smallest worthwhile differences were estimated from the standardised units multiplied by 0.2 . Probabilities were used to make a qualitative probabilistic mechanistic inference about the true effect, i.e., if the probabilities of the effect being substantially higher and lower were both $>5 \%$, the effect was reported as unclear. If not, the effect was clear and reported as the magnitude of the observed value. The scale was as follows: $25-75 \%$, possible; 75-95\%, likely; 95-99\%, very likely; >99\%, most likely (Hopkins et al., 2009).

\section{Results}

Table 1 and Figure $1(\mathrm{a}-\mathrm{c})$ present the results when comparing the $\left[0^{\prime}-10^{\prime}\right]$ versus $\left[10^{\prime}-20^{\prime}\right]$ game performance for the three condition games. Overall is presented a tendency of higher values, the $\left[0^{\prime}-10^{\prime}\right]$ compared with the $\left[10^{\prime}-20^{\prime}\right]$, and the results also show that as the previous players' knowledge about the tasks duration increases, the performance between two moments tends to be similar.

Considering the Unknown Condition, the players showed being from a likely $20.7 ; \pm 19.6 \%$ (mean difference $\% ; 90 \% \mathrm{CL}$ ) decrease in $\mathrm{H} / \mathrm{VH}$ ratio (small effect) to a most likely 27.3 ; $\pm 8.4 \%$ decrease in low ratio (moderate effect) when comparing the $\left[0^{\prime}-10^{\prime}\right]$ versus $\left[10^{\prime}-20^{\prime}\right]$.

In the Partially Condition, the difference between moments of performance decreased compared with the previous trend. However, there was still a solid tendency with an exception to the low ratio that presented an unclear result $(-6.6 ; \pm 12.2 \%$ variation, with unclear effect).

When the player knew the duration of tasks, the performance tended to be similar between game bouts, and also the inter-players' performance variabilities increased (as can be seen by the confidence intervals from effect sizes).

Table 2 and Figure $1(d-f)$ present the results when comparing the three conditions performance (for the entire 20' game

Table 1. Descriptive statistics when comparing $\left[0^{\prime}-10^{\prime}\right]$ vs. $\left[10^{\prime}-20^{\prime}\right]$ for the different condition game variables.

\begin{tabular}{|c|c|c|c|c|c|c|c|c|c|}
\hline \multirow[b]{2}{*}{ Variables } & \multicolumn{2}{|c|}{ Unknown } & \multirow{2}{*}{$\begin{array}{c}\text { Change in } \\
\text { mean (\%; } 90 \% \\
\text { CL) }\end{array}$} & \multicolumn{2}{|c|}{ Partially known } & \multirow{2}{*}{$\begin{array}{c}\text { Change in } \\
\text { mean (\%; } 90 \% \\
\text { CL) }\end{array}$} & \multicolumn{2}{|c|}{ Known } & \multirow[b]{2}{*}{$\begin{array}{c}\text { Change in mean } \\
(\% ; 90 \% \mathrm{CL})\end{array}$} \\
\hline & {$\left[0^{\prime}-10^{\prime}\right]$} & {$\left[10^{\prime}-20^{\prime}\right]$} & & {$\left[0^{\prime}-10^{\prime}\right]$} & {$\left[10^{\prime}-20^{\prime}\right]$} & & {$\left[0^{\prime}--10^{\prime}\right]$} & {$\left[10^{\prime}-20^{\prime}\right]$} & \\
\hline $\begin{array}{l}\text { Total distance } \\
\qquad\left(\mathrm{m} \cdot \mathrm{min}^{-1}\right)\end{array}$ & $107.9 \pm 14.3$ & $96.2 \pm 15.9$ & $\begin{array}{l}-11.2 ; \pm 2.9 \\
\text { Most likely } \downarrow\end{array}$ & $108.8 \pm 12.8$ & $102.3 \pm 15.5$ & $\begin{array}{l}-6.5 ; \pm 2.5 \\
\text { Likely } \downarrow\end{array}$ & $103.1 \pm 14.3$ & $99.1 \pm 10.7$ & $\begin{array}{l}-3.6 ; \pm 5.1 \\
\text { Possible } \downarrow\end{array}$ \\
\hline $\begin{array}{l}\text { Ratio (H/VH) } \\
(\mathrm{m})\end{array}$ & $19.2 \pm 12.5$ & $14.5 \pm 8.4$ & $\begin{array}{l}-20.7 ; \pm 19.6 \\
\text { Likely } \downarrow\end{array}$ & $25.9 \pm 13.4$ & $21.2 \pm 11.4$ & $\begin{array}{l}-22.9 ; \pm 10.8 \\
\text { Likely } \downarrow\end{array}$ & $21.0 \pm 11.6$ & $16.8 \pm 9.2$ & $\begin{array}{l}-23.9 ; \pm 34.1 \\
-\end{array}$ \\
\hline $\begin{array}{l}\text { Ratio (moderate) } \\
\quad(\mathrm{m})\end{array}$ & $78.3 \pm 29.8$ & $56.6 \pm 25.0$ & $\begin{array}{l}-29.6 ; \pm 6.9 \\
\text { Most likely } \downarrow\end{array}$ & $78.0 \pm 24.3$ & $67.0 \pm 24.6$ & $\begin{array}{l}-16.6 ; \pm 5.5 \\
\text { Very likely } \downarrow\end{array}$ & $66.1 \pm 26.6$ & $56.6 \pm 17.7$ & $\begin{array}{r}-12.2 ; \pm 15.0 \\
\text { Possible } \downarrow\end{array}$ \\
\hline $\begin{array}{l}\text { Ratio (low) } \\
\text { (m) }\end{array}$ & $58.2 \pm 16.7$ & $42.7 \pm 13.0$ & $\begin{array}{l}-27.3 ; \pm 8.4 \\
\text { Most likely } \downarrow\end{array}$ & $53.3 \pm 14.6$ & $50.2 \pm 14.4$ & $\begin{array}{l}-6.6 ; \pm 12.2 \\
-\end{array}$ & $47.1 \pm 16.2$ & $44.5 \pm 12.4$ & $\begin{array}{l}-4.9 ; \pm 14.6 \\
-\end{array}$ \\
\hline $\begin{array}{l}\text { Game pace } \\
\qquad\left(\mathrm{km} \cdot \mathrm{h}^{-1}\right)\end{array}$ & $6.5 \pm 0.9$ & $5.8 \pm 1.0$ & $\begin{array}{l}-11.1 ; \pm 3.1 \\
\text { Most likely } \downarrow\end{array}$ & $6.5 \pm 0.8$ & $6.1 \pm 0.9$ & $\begin{array}{l}-6.8 ; \pm 2.5 \\
\text { Very likely } \downarrow\end{array}$ & $6.3 \pm 0.9$ & $5.9 \pm 0.7$ & $\begin{array}{r}-6.3 ; \pm 2.3 \\
\text { Likely } \downarrow\end{array}$ \\
\hline $\begin{array}{l}\text { Total body } \\
\text { impacts } \\
\text { (au) }\end{array}$ & $137.1 \pm 37.2$ & $113.4 \pm 34.8$ & $\begin{array}{l}-17.7 ; \pm 7.6 \\
\text { Very likely } \downarrow\end{array}$ & $158.9 \pm 33.7$ & $133.5 \pm 43.3$ & $\begin{array}{l}-18.5 ; \pm 6.7 \\
\text { Most likely } \downarrow\end{array}$ & $146.4 \pm 46.6$ & $135.3 \pm 39.4$ & $\begin{array}{r}-6.0 ; \pm 8.1 \\
\text { Possible } \downarrow\end{array}$ \\
\hline
\end{tabular}

H/VH: High/Very high; CL: confidence limits; $\downarrow$ : decrease; $\uparrow$ : increase. 
(a) Unknown

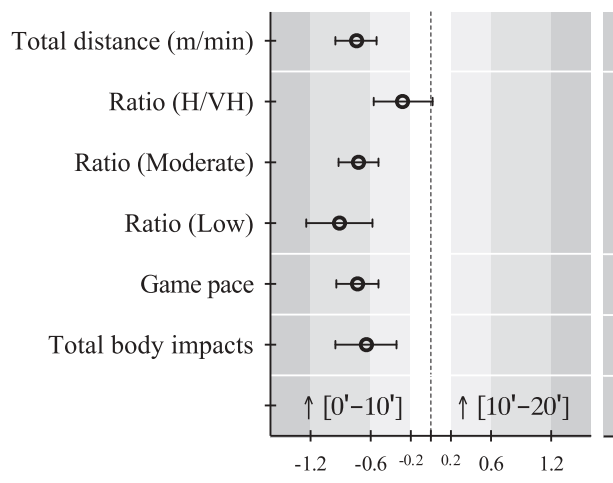

(d) Unknown vs Partially

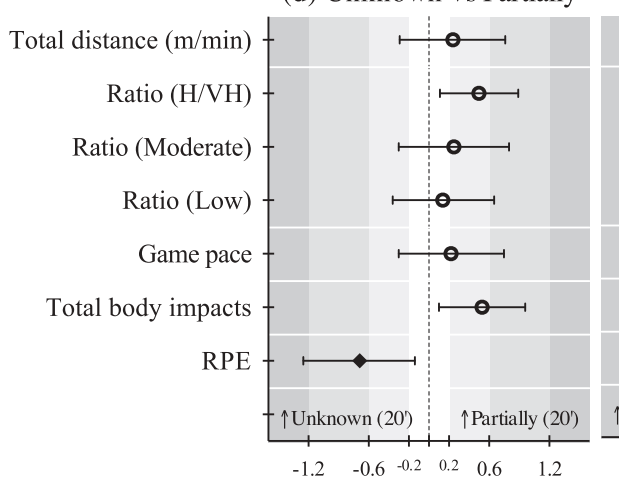

(b) Partially known

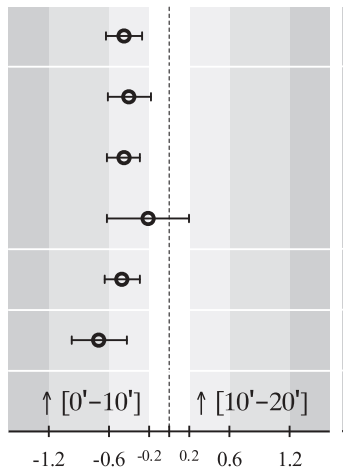

(e) Unknown vs Known

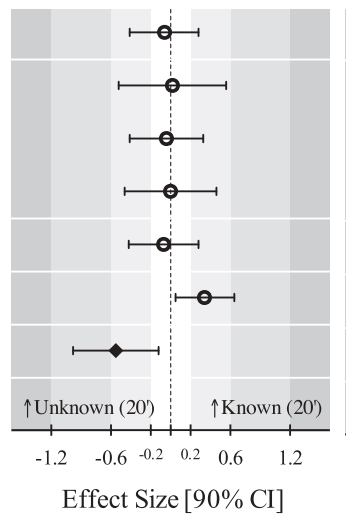

(c) Known

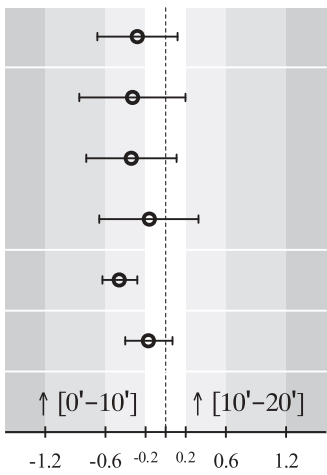

(f) Partially vs Known

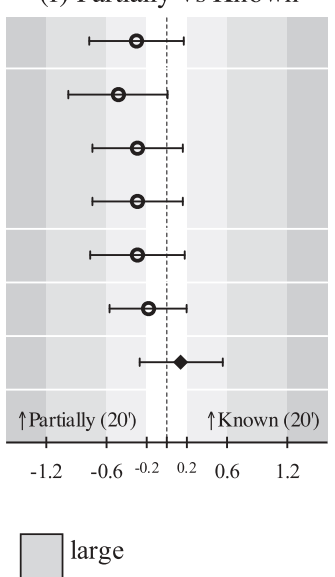

Figure 1. Comparative results of the $\left[0^{\prime}-10^{\prime}\right]$ vs. $\left[10^{\prime}-20^{\prime}\right]$ for the different condition game variables; and comparison between the different condition game variables during the $20^{\prime}$ game performance.

Table 2. Descriptive statistics when comparing the $20^{\prime}$ game different condition variables.

\begin{tabular}{|c|c|c|c|c|}
\hline Variables & Unknown (20' game) & Partially known (20' game) & Known (20' game) & Change in mean $(\% ; 90 \% \mathrm{CL})$ \\
\hline Total distance $\left(\mathrm{m} \cdot \mathrm{min}^{-1}\right)$ & $102.1 \pm 14.5$ & $105.5 \pm 13.9$ & $101.0 \pm 13.0$ & $\begin{array}{l}\text { a) } 3.5 ; \pm 7.9 \\
\text { b) }-0.9 ; \pm 5.0 \\
\text { c) }-4.3 ; \pm 6.6^{*}\end{array}$ \\
\hline Ratio $(\mathrm{H} / \mathrm{VH})(\mathrm{m})$ & $16.7 \pm 9.1$ & $23.5 \pm 11.7$ & $17.7 \pm 9.0$ & $\begin{array}{l}\text { a) } 49.1 ; \pm 47.7^{* *} \\
\text { b) } 1.5 ; \pm 45.2 \\
\text { c) }-31.9 ; \pm 27.6^{* *}\end{array}$ \\
\hline Ratio (moderate) (m) & $66.9 \pm 26.2$ & $72.4 \pm 23.8$ & $64.1 \pm 20.8$ & $\begin{array}{l}\text { a) } 10.8 ; \pm 24.9 \\
\text { b) }-1.6 ; \pm 14.8 \\
\text { c) }-11.2 ; \pm 16.4^{*}\end{array}$ \\
\hline Ratio (low) (m) & $50.0 \pm 13.5$ & $51.6 \pm 12.9$ & $50.2 \pm 14.6$ & $\begin{array}{l}\text { a) } 4.2 ; \pm 15.3 \\
\text { b) } 0.0 ; \pm 13.3 \\
\text { c) }-4.0 ; \pm 13.6\end{array}$ \\
\hline $\begin{array}{l}\text { Game pace } \\
\qquad\left(\mathrm{km} \cdot \mathrm{h}^{-1}\right)\end{array}$ & $6.1 \pm 0.9$ & $6.3 \pm 0.8$ & $6.1 \pm 0.8$ & $\begin{array}{l}\text { a) } 3.3 ; \pm 7.9 \\
\text { b) }-1.0 ; \pm 5.0 \\
\text { c) }-4.2 ; \pm 6.6^{*}\end{array}$ \\
\hline $\begin{array}{l}\text { Total body impacts } \\
\text { (au) }\end{array}$ & $250.5 \pm 65.9$ & $292.4 \pm 72.2$ & $281.7 \pm 82.4$ & $\begin{array}{l}\text { a) } 17.1 ; \pm 15.0^{* *} \\
\text { b) } 10.9 ; \pm 9.9^{* *} \\
\text { c) }-5.3 ; \pm 11.0\end{array}$ \\
\hline $\begin{array}{l}\mathrm{RPE} \\
\quad(\mathrm{au})\end{array}$ & $14.8 \pm 2.7$ & $13.3 \pm 1.5$ & $13.6 \pm 1.7$ & $\begin{array}{l}\text { a) }-8.7 ; \pm 8.3^{* *} \\
\text { b) }-6.9 ; \pm 5.7^{* *} \\
\text { c) } 2.1 ; \pm 7.0\end{array}$ \\
\hline
\end{tabular}

CL: Confidence limits; $\downarrow$ : decrease; $\uparrow$ : increase. Differences in means (\%; $\pm 90 \% \mathrm{CL}$ ) are identified as: (a) Unknown vs. Partially; (b) Unknown vs. Known; and (c) Partially vs. Known. ${ }^{*}$ Indicates the uncertainty in the true differences as follows * possible and ${ }^{* *}$ likely.

duration). The Partially Condition was the most demanding condition. When compared to Unknown, the Partially information increased $49.1 ; \pm 47.7 \%$ (likely, small effect) of the $\mathrm{H} / \mathrm{NH}$ values and $17.1 ; \pm 15.0 \%$ (likely, small effect) of the total body impacts. However, the players' RPE were likely lower $(-8.7 ; \pm 8.3 \%$, moderate). When comparing Partially versus Known, the higher difference was found in $\mathrm{H} / \mathrm{VH}$ with likely $31.9 ; \pm 27.6 \%$ (small effect) higher values to the Partially Condition. Finally, when comparing the Unknown versus Known Condition, the differences were declared unclear with respect to total body impacts (likely $10.9 ; \pm 9.9 \%$ higher in Known) and RPE (likely $6.9 ; \pm 5.7 \%$ higher in Unknown). 


\section{Discussion}

This study is the first to identify the influence of prior knowledge of exercise duration on the pacing patterns employed during small-sided games in soccer. In addition, it is the first to compare what happens in a longer duration of exercise. The main findings were that with an increase of the previous players' knowledge about the task duration, the general performance between the initial stage of exercise duration and the second one tended to be similar. Moreover, considering the entire $20^{\prime}$ game duration and the comparison between the three conditions performances, the partial knowledge condition (Partially Condition) of the exercise was the most demanding condition.

Primarily, our findings are in line with studies that reported that player pacing patterns are influenced by the duration knowledge of the exercise (Billaut et al., 2011; Gabbett et al., 2015; Lambert, Gibson, \& Noakes, 2005; Lander, Butterly, \& Edwards, 2009). According to these studies, it seems that the brain initiates a self-regulation strategy of effort based on prior knowledge of the task and this fact can explain the sport-specific fitness of both greater total and higher intensity work. Also in our study, it seems to have been a conscious or unconscious mechanism of regulation that led to changes in performance on the basis of previous different pieces of information provided. Based on the decision-making model by Simon (1955) as suggested by Renfree et al. (2014), the knowledge of exercise duration in this case seems to influence the decision to reduce or increase efferent neural drive, observed by an decrease or increase in physical performance, probably based on the degree of uncertainty or certainty concomitant and the degree of potential homeostasis disruption perceived in each condition.

Comparing the initial $[10 \mathrm{~min}$ ] exercise period and the second for the three conditions, the initial [10 $\mathrm{min}$ ] exercise period has higher values. Primarily and according to the literature and from a physiological point of view, this can be explained by the effect of accumulated fatigue during the exercise time, probably due to the accumulation of $\mathrm{H}+$ that contributes to decreased muscle $\mathrm{pH}$, which impairs the cellular process that produces energy and muscle contraction. However, we can also conclude that seems the players adopted a "slow positive" pacing profile characterised by a gradual decline in total and high-intensity running between the initial $[10 \mathrm{~min}$ ] exercise period and the second (Waldron \& Highton, 2014). Moreover, the differences between the [0'-10'] versus $\left[10^{\prime}-20^{\prime}\right]$ tend to decrease when knowledge of exercise duration increases. This means that most of the variables have a tendency to be higher in the initial $[10 \mathrm{~min}$ ] exercise period of exercise but there is a better balance in the regulation of effort when the knowledge is greater.

Gabbett et al. (2015) found similar results with a significant effect of condition and time on the relative intensity of the small-sided games with higher initial intensities, although there is no correspondence comparing the results of different groups/conditions in relation to our study. Protocol differences and the specificity of each sport perhaps can influence the results of each condition. Likewise, the results may confirm the possibility of the changes in the pacing patterns of the players due to the effect of knowledge leading to the possibility of the non-linearity of the fatigue effect already pointed out in some studies (Ferraz et al., 2012; Millet, 2011).

Similarly, and according to the study of Millet (2011) applied in ultra-marathon running, it is possible that the players control their effort in order to increase their performance during the exercise as a result of a more aggressive regulation strategy, possibly due to having the knowledge of the exercise duration (partially or totally), despite the physiological accumulation of fatigue.

When we compared the three different performance conditions for the entire 20-min game duration, we found that the Partially Condition always presents a tendency to higher values of all variables when compared with the other conditions, except RPE. Seems the players adopted the "all-out" or "reserve" pacing pattern (more aggressive pacing pattern) (Waldron \& Highton, 2014) when they knew the partial duration time (Partially Condition). These results are not fully consistent with the findings of Gabbett et al. (2015). In this study, there is no condition that always shows better or the same results compared to the other conditions, perhaps due to reasons already mentioned.

However, and in line with Billaut et al. (2011), when the players were deceived so as to believe that they had to perform only $10 \mathrm{~min}$ (i.e., the Partially Condition), they probably produced higher power and work than in the two other conditions, and it's possible that there was a greater subconscious neural drive, probably because of the reduced time duration of exercise, which led to greater muscle recruitment and thus greater performance output. These results reinforce the possibility that the control of the initial exercise performance was, at least in part, regulated in anticipation of the exercise. This anticipation according to Billaut et al. (2011) would have been based on the knowledge of the duration of the exercise performance, which may be considered in the present study as the end point of the exercise (Noakes, Gibson, \& Lambert, 2005; St Clair Gibson et al., 2006; St Clair Gibson \& Noakes, 2004).

Moreover, it was expected that RPE values were higher in the Partially Condition due to the possibility that a greater conscious perception of effort occurs when the ratio of highspeed-running intensity is higher (Edwards \& Noakes, 2009) due to the knowledge of a shorter exercise duration (Gabbett et al., 2015). Therefore, we can also consider that in the Unknown Condition, RPE values would be lower (Billaut et al., 2011). Corroborating these hypotheses, Tucker (2009) suggested that RPE is a key mediator in the regulation of work rate during continuous exercise based on the anticipatory feedback model.

The anticipatory feedback model of performance suggests that the brain (which plays a role in most types of fatigue) may continuously compare the consciously perceived exertion generated from the sum of all afferent cues with a RPE "template" based on prior knowledge (Tucker, 2009) preceding physiological fatigue. Baden, McLean, Tucker, Noakes and Gibson (2005) have suggested that changes in RPE are the result of affective processes responding to an unexpected sudden increase in exercise duration or the sudden imposition of a mismatch between the previously anticipated and the newly required exercise duration (similar to our Partially Condition). Also according psychobiological model by Marcora (2008, 2009), 
RPE is a determinant key in regulation of exercise performance. According to this model, the conscious regulation of pace is primarily determined by the effort perceived by the athlete. When the perception of effort is changed, the athlete will consciously change its pace to compensate for the negative/ positive effect, leading to an improvement or impairment in self-paced performance. However, and contrary to expectations, RPE values were significantly higher in the Unknown Condition compared with the other conditions, in which they presented similar values, not showing corresponding values to the demands of exercise and not following the anticipatory feedback model theory or psychobiological model.

To this purpose, some studies have also shown that perceived exertion may be a psychological construct that is altered by changes in affect and cognitive focus of the athlete (Baden et al., 2005; Gibson et al., 2006). Also Renfree et al. (2014) states that there is a substantial evidence that the conscious RPE can be dissociated from physiological processes throughout a variety of purely psychological mechanisms and this finding suggests that if self-paced exercise performance is regulated via the conscious RPE, then some individuals may be likely to make poor decisions regarding selection of appropriate self-pace intensity of exercise. Indeed seems a pertinent question if the RPE can be really considered or not a true gestalt at all (Hutchinson \& Tenenbaum, 2006) and if not be an oversimplification of the psychophysiological construct and insufficient measure to capture the wide range of sensations experience as pointed by Renfree et al. (2014), especially in team sports as a soccer or in activities related as a SSG.

Thereby, is possible that in our study, the Unknown Condition probably leads to a perception of greater effort which is also reflected in practise and in RPE values. The other conditions tend to be similar, perhaps because the knowledge of exercise duration changed the cognitive focus of the player, leading him to a more conscientious perception of effort. Thus, we can suppose that a direct association between exercise intensity and RPE values may not always occur. In order to clarify, this point seems to be important to measure RPE during SSG in future studies, aspect that we can point as a limitation in the present study. Moreover, it would be important a deeper understanding of the role of RPE in the exercise regulation, in particular, to clarify the role of RPE as a regulator and/or quantifier measure.

Furthermore and still considering the entire 20 min game duration, results show that having or not having full knowledge cannot significantly influence the final performance of the exercise, and having only partial knowledge (knowledge of $10 \mathrm{~min}$ ) may lead to increased performance. In fact, we also consider it plausible that with the increase of exercise duration, the regulation of effort appears to become less accurate, more uncertain and because of this, it becomes economic. This also shows that the duration time of exercise can be an important factor regarding pacing patterns. Longer exercise duration, even with full knowledge of this duration, probably leads to a greater uncertainty in the effort regulation and an increase of exercise economy, compared to short-term exercise duration. The pacing pattern between unknown condition and known condition therefore tends to be similar probably because the degree of uncertainty in both conditions may be very similar.

In this sense, it seems that the physical performance of intermittent exercise in soccer is probably higher in shortterm exercises with partial knowledge of the information. But more studies are needed to confirm all of these assumptions.

\section{Conclusions}

This study provides some evidence that during small-sided games in soccer, athletes alter their pacing patterns based on the knowledge of the exercise duration. Furthermore, the knowledge of a shorter duration seems to lead to an increase of exercise duration demand, and longer exercise durations possibly tend to decrease differences between full knowledge and not knowing the exercise duration. In fact, the knowledge of duration of exercise seems to be an important variable in pacing patterns in soccer, and coaches should consider the potential and the possibilities of the manipulation of this variable in terms of the physical impact regulation in their training exercises.

\section{Practical applications}

This study highlights the importance of the knowledge of exercise duration on pacing patterns in soccer and objectively in the physical performance of players. The coaches can manipulate this variable in order to manage the fatigue effect in exercise and this can be an important point to add in terms of the methodology of soccer training, specifically in preparation and control of the training tasks. For example, if the coach wants to keep a high physical performance of the exercise, he should choose short durations and inform the players previously about these task durations. But if he wants a more balanced effort management during the entire time of the exercise, he should enhance the duration of the exercise and also inform players about this task duration. Similarly, and according to the technical and/or tactical objectives of the exercise, the coach can develop these objectives in different situations of fatigue, manipulating the duration of the exercise and the information about this duration. For example, if the coach wants to create an exercise with fewer physical requirements and allows a greater physical availability to learning the other aspects during the duration, he should choose a longer exercise (e.g., $20 \mathrm{~min}$ ), giving prior information to the players about the duration of it. But if he wants to develop tactical/ technical content, with a greater physical performance scenario, he should perform the exercise in shorter blocks of duration, giving prior information about the time duration of each block (e.g., $10 \mathrm{~min}+10 \mathrm{~min}$ ). Future studies should use the potential of this issue and provide information to coaches adding other training variables (e.g., technical and tactical aspects).

\section{Acknowledgements}

This work was supported by the Portuguese Foundation for Science and Technology (FCT) and European Social Fund (ESF), through a Doctoral grant endorsed to the first author (SFRH/BD/71470/2010) under the Human Potential Operating Program (POPH); and through the research 
Project Symbiotic technology for societal efficiency gains: Deus ex Machina, NORTE-01-0145-FEDER-000026, co-financed by Fundo Europeu de Desenvolvimento Regional (FEDER) - NORTE 2020.

\section{Disclosure statement}

No potential conflict of interest was reported by the authors.

\section{Funding}

This work was supported by the Portuguese Foundation for Science and Technology (FCT) and European Social Fund (ESF), through a Doctoral grant endorsed to the first author [SFRH/BD/71470/2010] under the Human Potential Operating Program (POPH) [SFRH/BD/71470/2010]; Research Project Symbiotic technology for societal efficiency gains: Deus ex Machina, NORTE-01-0145-FEDER-000026, co-financed by Fundo Europeu de Desenvolvimento Regional (FEDER) - NORTE 2020: [NORTE01-0145-FEDER-000026].

\section{ORCID}

Ricardo Ferraz (D) http://orcid.org/0000-0002-7530-512X

Bruno Gonçalves (iD) http://orcid.org/0000-0001-7874-4104

Jaime Sampaio (D) http://orcid.org/0000-0003-2335-9991

Mário Cardoso Marques (D) http://orcid.org/0000-0002-5812-1580

\section{References}

Abade, E. A., Gonçalves, B. V., Leite, N. M., \& Sampaio, J. E. (2014). Timemotion and physiological profile of football training sessions performed by under-15, under-17, and under-19 elite portuguese players. International Journal of Sports Physiology and Performance, 9(3), 463470. doi:10.1123/ijspp.2013-0120

Baden, D. A., McLean, T. L., Tucker, R., Noakes, T. D., \& Gibson, A. S. C. (2005). Effect of anticipation during unknown or unexpected exercise duration on rating of perceived exertion, affect, and physiological function. British Journal of Sports Medicine, 39(10), 742-746. doi:10.1136/bjsm.2004.016980

Billaut, F., Bishop, D. J., Schaerz, S., \& Noakes, T. D. (2011). Influence of knowledge of sprint number on pacing during repeated-sprint exercise. Medicine and Science in Sports and Exercise, 43(4), 665-672. doi:10.1249/ MSS.0b013e3181f6ee3b

Borg, G. A. (1973). Perceived exertion: A note on "history" and methods. Medicine and Science in Sports, 5(2), 90-93.

Cumming, G. (2012). Understanding the new statistics: Effect sizes, confidence intervals, and meta-analysis. New York, NY: Routledge, Taylor \& Francis Group.

Edwards, A., \& Polman, R. (2014). Pacing in sport and exercise: A psychophysiological perspective. New York, NY: Nova Biomedical.

Edwards, A. M., \& Noakes, T. D. (2009). Dehydration: Cause of fatigue or sign of pacing in elite soccer? Sports Medicine, 39(1), 1-13. doi:10.2165/ 00007256-200939010-00001

Ferraz, R., Van Den Tillaar, R., \& Marques, M. C. (2012). The effect of fatigue on kicking velocity in soccer players. Journal of Human Kinetics, 35, 97107. doi:10.2478/v10078-012-0083-8

Ferraz, R., Van Den Tillaar, R., \& Marques, M. C. (2015). The influence of different exercise intensities on kicking accuracy and velocity in soccer players. Journal of Sport and Health Science. doi:10.1016/j. jshs.2015.10.001

Ferraz, R., Van Den Tillaar, R., Pereira, A., \& Marques, M. C. (2016). The effect of fatigue and duration knowledge of exercise on kicking performance in soccer players. Journal of Sport and Health Science. doi: 10.1016/j. jshs.2016.02.001

Gabbett, T. J., Walker, B., \& Walker, S. (2015). Influence of prior knowledge of exercise duration on pacing strategies during game-based activities. International Journal of Sports Physiology and Performance, 10(3), 298304. doi:10.1123/ijspp.2013-0543
Gibson, A. S. C., Lambert, E. V., Rauch, L. H. G., Tucker, R., Baden, D. A., Foster, C., \& Noakes, T. D. (2006). The role of information processing between the brain and peripheral physiological systems in pacing and perception of effort. Sports Medicine (Auckland, N.Z.), 36(8), 705-722. doi:10.2165/00007256-200636080-00006

Gibson, A. S. C., \& Noakes, T. D. (2004). Evidence for complex system integration and dynamic neural regulation of skeletal muscle recruitment during exercise in humans. British Journal of Sports Medicine, 38 (6), 797-806. doi:10.1136/bjsm.2003.009852

Hopkins, W. G., Marshall, S. W., Batterham, A. M., \& Hanin, J. (2009). Progressive statistics for studies in sports medicine and exercise science. Medicine and Science in Sports and Exercise, 41(1), 3-12. doi:10.1249/MSS.0b013e31818cb278

Hutchinson, J. C., \& Tenenbaum, G. (2006). Perceived effort - can it be considered gestalt? Psycology of Sport and Exercise, 7, 463-476. doi:10.1016/j.psychsport.2006.01.007

Johnston, R. J., Watsford, M. L., Pine, M. J., Spurrs, R. W., Murphy, A. J., \& Pruyn, E. C. (2012). The validity and reliability of 5-hZ global positioning system units to measure team sport movement demands. Journal of Strength and Conditioning Research, 26, 758-765. doi:10.1519/ JSC.0b013e318225f161

Lambert, E. V., Gibson, A. S. C., \& Noakes, T. D. (2005). Complex systems model of fatigue: Integrative homoeostatic control of peripheral physiological systems during exercise in humans. British Journal of Sports Medicine, 39, 52-62. doi:10.1136/bjsm.2003.011247

Lander, P. J., Butterly, R. J., \& Edwards, A. M. (2009). Self-paced exercise is less physically challenging than enforced constant pace exercise of the same intensity: Influence of complex central metabolic control. British Journal of Sports Medicine, 43(10), 789-795. doi:10.1136/bjsm.2008.056085

Marcora, S. M. (2008). Do we really need a central governor to explain brain regulation of exercise performance? European Journal of Applied Physiology, 104, 929-931. doi:10.1007/s00421-008-0818-3

Marcora, S. M. (2009). Perception of effort during exercise is independent of afferent feedback from skeletal muscles, heart, and lungs. Journal of Applied Physiology, 106, 2060-2062. doi:10.1152/japplphysiol.90378.2008

McLellan, C. P., Lovell, D. I., \& Gass, G. C. (2011). Biochemical and endocrine responses to impact and collision during elite rugby league match play. The Journal of Strength \& Conditioning Research, 25(6), 1553-1562. doi:10.1519/JSC.0b013e3181db9bdd

Millet, G. Y. (2011). Can neuromuscular fatigue explain running strategies and performance in ultra-marathons?: The flush model. Sports Medicine, 41(6), 489-506. doi:10.2165/11588760-000000000-00000

Mohr, M., Krustrup, P., \& Bangsbo, J. (2003). Match performance of highstandard soccer players with special reference to development of fatigue. Journal of Sports Sciences, 21(7), 519-528. doi:10.1080/ 0264041031000071182

Mohr, M., Krustrup, P., \& Bangsbo, J. (2005). Fatigue in soccer: A brief review. Journal of Sports Sciences, 23(6), 593-599. doi:10.1080/02640410400021286

Noakes, T. D., Gibson, A. S. C., \& Lambert, E. V. (2005). From catastrophe to complexity: A novel model of integrative central neural regulation of effort and fatigue during exercise in humans: summary and conclusions. British Journal of Sports Medicine, 39(2), 120-124. doi:10.1136/ bjsm.2003.010330

Reilly, T., Drust, B., \& Clarke, N. (2008). Muscle fatigue during football match-play. Sports Medicine, 38(5), 357-367. doi:10.2165/00007256200838050-00001

Renfree, A., Martin, L., Micklewright, D., \& Gibson, A. S. C. (2014). Application of decision-making theory to the regulation of muscular work rate during self-paced competitive endurance activity. Sports Medicine, 44, 147-158. doi:10.1007/s40279-013-0107-0

Simon, H. A. (1955). A behavioral model of rational choice. Quarterly Journal of Economics, 69(1), 99-118. doi:10.2307/1884852

Tucker, R. (2009). The anticipatory regulation of performance: The physiological basis for pacing strategies and the development of a perception-based model for exercise performance. British Journal of Sports Medicine, 43(6), 392-400. doi:10.1136/bjsm.2008.050799

Waldron, M., \& Highton, J. (2014). Fatigue and pacing in high-intensity intermittent team sport: An update. Sports Medicine, 44, 1645-1658. doi:10.1007/s40279-014-0230-6 